MR. BRANDON FRITZ (Orcid ID : 0000-0001-5856-0527)

Article type : Original Research Article

\title{
Genetic Selection for Alcohol Preference in Mice Alters Dorsal Striatum Neurotransmission
}

Brandon M. Fritz¹, Braulio Munoz¹, \& Brady K. Atwood ${ }^{1,2}$

${ }^{1}$ Department of Pharmacology \& Toxicology, ${ }^{2}$ Stark Neurosciences Research Institute, Indiana University School of Medicine, 320 West 15 ${ }^{\text {th }}$ St, Indianapolis, IN, USA 46202.

Correspondence:

Brady K. Atwood

Indiana University School of Medicine

NB $400 C$

$320 \mathrm{~W} 15^{\text {th }}$ St.

Indianapolis, IN, USA 46202

Tel: 317-274-8917

Fax: 317-274-7714

This is the author's manuscript of the article published in final edited form as:

Fritz, B. M., Munoz, B., \& Atwood, B. K. (2019). Genetic Selection for Alcohol Preference in Mice Alters Dorsal Striatum Neurotransmission. Alcoholism: Clinical and Experimental Research, 0(ja). https://doi.org/10.1111/acer.14187 
Email: bkatwood@iu.edu

\section{ABSTRACT}

Background: Although it is widely acknowledged that the risk of developing an alcohol use disorder (AUD) is strongly influenced by genetic factors, very little is known about how this genetic predisposition may alter neurotransmission in a way that promotes AUD susceptibility. The dorsal striatum has garnered increased attention as a brain region of 
interest in AUD development given its significant roles in goal-directed and habitual behavior.

Methods: In the present work, dorsal striatal neurotransmission parameters were measured in preclinical mouse models of high and low AUD risk. We performed brain slice whole-cell patch clamp electrophysiological recordings from medium spiny neurons (MSNs) in the dorsomedial (DMS) and dorsolateral (DLS) striatum of naïve adult male and female selectively-bred high and low alcohol-preferring lines of mice (HAP and LAP).

Results: We found that MSNs of HAP mice were significantly more excitable than those of LAP mice, specifically in the DLS. Additionally, the frequencies of spontaneous glutamateand GABA-mediated currents were both elevated in HAP mice relative to LAP mice in both dorsal striatal subregions, whereas amplitude differences were more variable between lines and subregions. AMPAR/NMDAR current ratios were significantly lower in HAP mice in both DLS and DMS.

Conclusions: Collectively, these results suggest that genetic predisposition for high or low alcohol consumption produces significantly different basal functional states within both DLS and DMS which may be important factors in the behavioral phenotypes of HAP and LAP mice.

Keywords: Alcohol, dorsal striatum, genetics, glutamate, GABA, mice 


\section{INTRODUCTION}

An individual's risk for developing an Alcohol Use Disorder (AUD) is heavily influenced by his or her genetic background. In fact, the relative 'density,' or pervasiveness of AUD diagnosis in an individual's family is positively related to the likelihood of future problematic alcohol use (Kendler et al., 2018). This association is especially strong if one or both parents reach AUD diagnostic criteria. An analysis of a large United States sample determined that having one parent with AUD produced a 2.5-fold increase in risk for AUD development, whereas having both parents with AUD resulted in a 4.4-fold increase in risk (Yoon et al., 2013). This heavy genetic load, along with the inherent complexity of AUD, suggests that this predisposition likely manifests in neurobiological and neurophysiological alterations.

The dorsal striatum is a prominent brain region of interest in the etiology of AUD, composed of $\sim 95 \%$ GABAergic medium spiny projection neurons (MSNs) (Tepper and Bolam, 2004), and is the primary input nucleus of the basal ganglia. The dorsal striatum can be anatomically divided into medial (DMS) and lateral (DLS) subregions, each receiving unique excitatory glutamatergic inputs from diverse cortical regions and thalamic nuclei as well as from basolateral amygdala (Hunnicutt et al., 2016). Both human and animal studies demonstrate that the DMS and DLS are also functionally heterogeneous, with the DMS having a prominent role in goal-directed learning whereas the DLS is important in habit learning (Balleine and O'Doherty, 2010; Tricomi et al., 2009; Yin et al., 2004). Aberrant function in each of these regions has been hypothesized to have relevance for problematic drug and alcohol (ethanol) use, with the DMS promoting hyper goal-directed behavior aimed at substance use/seeking (Cheng et al., 2017; Nam et al., 2013), and the DLS driving the development of habitual use/seeking (Everitt and Robbins, 2016).

Human imaging studies reveal elevated blood oxygen levels (putative neural activity) in the dorsal striatum of heavy drinking individuals (including those with AUD) relative to social drinkers in response to alcohol-related cues (Vollstadt-Klein et al., 2010). 
Furthermore, individuals with AUD demonstrate an overreliance on habit learning coupled with increased activation of the posterior putamen (analogous to the DLS) during an instrumental learning task (Sjoerds et al., 2013). Preclinical studies also demonstrate that the DMS regulates goal-directed alcohol seeking whereas the DLS regulates habitual alcohol seeking (Corbit et al., 2012, 2014). Furthermore, alcohol exposure can differentially influence synaptic input to and plasticity within both dorsal striatum subregions (Adermark et al., 2011; Munoz et al., 2018; Wang et al., 2010; Wilcox et al., 2014), thus having the potential to influence how an individual interacts with alcohol with repeated use.

The above findings inspire an important question: does genetic predisposition for AUD manifest as aberrant dorsal striatum function in a manner that may increase the risk of AUD development? Human work has primarily focused on the ventral striatum and altered function is indeed observed in children of one or more parents with AUD (Bjork et al., 2008; Heitzeg et al., 2010). However, whether functional differences in the dorsal striatum subregions exist prior to alcohol exposure in individuals predisposed to AUD development remains unclear. One challenge of human imaging work is the broad nature of its analysis. Preclinical techniques employing animal models (e.g. electrophysiology) allow for direct measurement of neural activity within the brain region(s) of interest and have the power to address mechanisms of functional differences. To address the question posed above, the current study comparatively assessed functional differences in DMS and DLS neurotransmission in mouse models of divergent genetic risk for AUD development.

\section{METHODS}

Animals

Naïve adult (postnatal day 60-115) mice from the genetically-selected high and low alcohol-preferring mouse lines (HAP and LAP) were used. Detailed information regarding the derivation and drinking behavior of these lines can be found elsewhere (Matson and Grahame, 2013; Oberlin et al., 2011). Briefly, these lines have been selectively-bred for many generations from a common outbred stock (HS/lbg) for high or low alcohol preference

This article is protected by copyright. All rights reserved 
in a 2-bottle choice drinking paradigm. HAP mice demonstrate nearly complete preference for the alcohol solution over water ( $90-95 \%$ preference) and reach blood alcohol concentrations in excess of $80 \mathrm{mg} / \mathrm{dl}$, whereas LAP mice are nearly complete abstainers (< $5 \%$ preference). These lines thus model divergent genetic predisposition for excessive alcohol intake and avoidance. HAP mice also exhibit other AUD-relevant phenotypes relative to LAP mice such as heightened impulsivity (Oberlin and Grahame, 2009), enhanced alcohol tolerance capacity (Fritz and Boehm, 2014; Fritz et al., 2013), and a propensity for binge-like alcohol consumption (Linsenbardt and Boehm, 2015). In selective breeding studies, these associated phenotypes are referred to as 'correlated responses' to selection. For the current work, mice from replicates 2 and 3 of selection were used (HAP2/HAP3 and LAP2/LAP3). A 'replicate' line is one where selective breeding from the outbred stock was repeated to, in part, ensure that the selection phenotype (alcohol preference) is reliably produced. The observation of line differences within one or more replicate lines is considered evidence for a genetically correlated response (Crabbe et al., 1990), with more consistency across replicates providing increasingly strong evidence. Given that the LAP1 line is extinct, replicate 1 mice were not used in the current study because no genetic comparison could be made.

\section{Electrophysiology}

Mice were deeply anesthetized via isoflurane and decapitated. Brain tissue was then rapidly excised and transferred to an ice-cold, oxygenated $\left(95 \% \mathrm{CO}_{2} / 5 \% \mathrm{O}_{2}\right.$ bubbled) cutting solution containing (mM): $30 \mathrm{NaCl}, 4.5 \mathrm{KCl}, 1 \mathrm{MgCl}_{2}, 26 \mathrm{NaHCO}_{3}, 1.2 \mathrm{NaH}_{2} \mathrm{PO}_{4}, 10$ glucose, and 194 sucrose. $280 \mu \mathrm{m}$ coronal brain slices containing the striatum were prepared on a Leica VT1200S vibratome. Sections were rapidly transferred to $32^{\circ} \mathrm{C}$, oxygenated artificial cerebrospinal fluid (aCSF) containing (mM): $124 \mathrm{NaCl}, 4.5 \mathrm{KCl}, 2 \mathrm{CaCl} 2,1 \mathrm{MgCl} 2,26$ NaHCO3, 1.2 NaH2PO4 and 10 glucose.

Whole-cell voltage and current clamp recordings were made using a Multiclamp 700B amplifier and Digidata 1550B (Molecular Devices, Sunnyvale, CA, USA). For recording, brain slices were moved to a recording chamber, held at $32^{\circ} \mathrm{C}$, and continuously perfused 
with oxygenated aCSF at a rate of $\sim 1.5 \mathrm{ml} / \mathrm{min}$. Slices were visualized on an Olympus BX51WI microscope (Olympus Corporation of America). MSNs in the DMS and DLS were confirmed by their membrane resistance and capacitance. Borosilicate glass recording pipettes of 2-4 MS were filled with specific internal solutions (see below, adjusted to 295$310 \mathrm{mOsm}$ ) for whole-cell recordings. All recordings were filtered at $2.2 \mathrm{kHz}$ and digitized at $10 \mathrm{kHz}$. Data were acquired using Clampex 10 software (Molecular Devices). Series resistance was continuously monitored and only cells with a stable access resistance (less than $25 \mathrm{M} \Omega$ and that did not change more than 15\%) were included for data analysis.

\section{Excitability}

Cells were recorded in current clamp mode, allowing them to sit at their natural resting membrane potential. Increasing current steps $(-200 \mathrm{pA}$ to $+400 \mathrm{pA}$ in $50 \mathrm{pA}$ increments) were injected for $500 \mathrm{~ms}$ every $10 \mathrm{~s}$. The following excitability parameters were measured: resting membrane potential (RMP), input resistance, action potential (AP) threshold potential, AP peak, AP half-width, and AP frequency. For the AP threshold potential, AP peak, and AP half-width parameters, data from the first current step that produced APs were used. A K-gluconate internal solution was used and contained (mM): $4 \mathrm{KCl}, 10 \mathrm{HEPES}, 4 \mathrm{MgATP}, 0.3 \mathrm{NaGTP}, 10$ phosphocreatine, $126 \mathrm{~K}$-gluconate.

\section{Excitatory transmission}

To isolate excitatory transmission, the aCSF contained $50 \mu \mathrm{M}$ picrotoxin. Recordings were conducted in voltage clamp mode and cells were held at $-60 \mathrm{mV}$ (unless otherwise indicated). The internal solution for excitatory recordings contained (mM): $120 \mathrm{CsMeSO} 3$, $5 \mathrm{NaCl}, 10$ TEA-Cl, 10 HEPES, 5 lidocaine bromide, 1.1 EGTA, $0.3 \mathrm{Na}-\mathrm{GTP}$ and $4 \mathrm{Mg}$-ATP. After a stabilization period of at least 10 minutes, spontaneous excitatory postsynaptic currents (sEPSCs) were measured over the course of 5-min gap-free recordings.

Parameters measured included: sEPSC amplitude, frequency, rise-time, and decay constant. 
The ratio of glutamate-driven $\alpha$-amino-3-hydroxy-5-methyl-4-isoxazolepropionic acid (AMPA) receptor to $\mathrm{N}$-methyl-D-aspartate (NMDA) receptor current was also assessed in voltage-clamp mode. A Teflon-coated bipolar stimulating electrode (PlasticsONE, Roanoke, VA, USA) was placed at the border of the corpus callosum and the DMS or DLS (Figures 1A and $2 \mathrm{~A}$ ). Neurons were held at a $-60 \mathrm{mV}$ holding potential and EPSCs were evoked via a DS3 Isolated Current Stimulator (Digitimer, Ft. Lauderdale, FL, USA) and the intensity was adjusted until a stable response between -200 and -400 pA was observed. The holding potential was then changed to $-80 \mathrm{mV}$ to isolate AMPA currents and 10 EPSCs were evoked (20 s inter-stimulus interval). The AMPA receptor antagonist NBQX (Tocris Bioscience, Bristol, UK) was then perfused onto the slice at a concentration of $5 \mu \mathrm{M}$ until AMPA receptor-mediated currents were no longer evident. The holding potential was then adjusted to $+60 \mathrm{mV}$ to isolate NMDA receptor-driven currents and 10 more EPSCs were evoked (20s inter-stimulus interval). The ratio of mean AMPA receptor current peak was then compared to the mean NMDA receptor current peak.

\section{Inhibitory Transmission}

To isolate inhibitory transmission, the aCSF contained $5 \mu \mathrm{M} \mathrm{NBQX}$ and $50 \mu \mathrm{M}$ AP-5 (NMDA receptor antagonist; Tocris Bioscience, Bristol, UK). Inhibitory recordings were conducted in voltage clamp mode and cells were held at $-60 \mathrm{mV}$. After a stabilization period of at least 10 minutes, spontaneous inhibitory postsynaptic currents (sIPSCs) were measured over the course of 3-min gap-free recordings. SIPSC recordings yielded many more postsynaptic events and were therefore shorter than sEPSC recordings. Parameters measured included: sIPSC amplitude, frequency, rise-time, and decay constant. The Csbased internal solution of inhibitory recordings contained (mM): $120 \mathrm{CsCl}_{2}, 10 \mathrm{HEPES}$, 10 EGTA, $4 \mathrm{MgCl}_{2}$, $2 \mathrm{MgATP}, 0.5 \mathrm{NaGTP}$, and 5 lidocaine.

Electrophysiology Data Processing and Statistical Analysis 
All excitability and AMPA/NMDA ratio data were processed via pClamp 10.6 software. sEPSC and sIPSC data were processed via MiniAnalysis software (Synaptosoft Inc.). Statistical analyses were conducted via Statistica 7 software (Statsoft, Tulsa, OK). Statistical outliers were determined via Grubb's test. Out of a total of 649 cells, 23 met criteria as outliers (3.5\% of total population) and were removed from their respective analysis. DMS and DLS data were analyzed separately. Analyses of variance (ANOVAs) were used for all analyses and included line (HAP/LAP), sex (M/F), and replicate (2/3) as factors. Analyses were collapsed on sex where it was found to not be a significant factor. The significance level for all analyses was set at $p<0.05$ and Tukey-Kramer post hoc statistics were run where applicable. Any main effects or possible interactions that are not reported did not reach statistical significance. It is important to bear in mind that main effects of replicate are both expected and not particularly relevant to our genetic hypothesis. Due to the logistical limitation of mouse colony size, genetic drift occurs over many generations in selected lines and some alleles not relevant to the selection phenotype (alcohol preference in this case) become fixed. As a result, replicates (e.g. replicate 2 vs. replicate 3 ) may be observed to differ in a variety of experimental measures. So long as there is no interaction with line, this effect has no relationship to the selection phenotype. As such, the details of all main effects of replicate can be found in Table S1 and are not noted in the figures. Finally, as our main hypotheses were driven by the behavioral genetics of HAP and LAP mice, figures are presented collapsed on sex to highlight where line differences occurred. Sex effects and interactions are also detailed in Table S1.

\section{RESULTS}

\section{Excitability}

Within the DLS (Figure 1A), analysis determined no effect of line on MSN RMP $\left(p>0.05\right.$; Figure 1B). Replicate $\left(F_{1,66}=41.95, p<0.001\right.$; Table S1) and $\operatorname{sex}\left(F_{1,66}=5.07, p<0.05\right.$; Table S1) were significant factors with female and replicate 3 cells exhibiting more depolarized RMPs. A significant line $\times$ replicate $\times$ sex interaction $\left(F_{1,66}=5.1, p<0.05\right.$; Table S1) also indicated that within HAP3 mice, female DLS cells sat at a more depolarized RMP 
relative to male cells. HAP MSNs exhibited significantly greater input resistance compared to LAP cells $\left(F_{1,66}=3.978, p=0.05\right.$; Figure $\left.1 C\right)$, indicating that current was translated into larger changes in voltage across the membrane. Increasingly positive current steps also revealed that HAP MSNs fired APs at a significantly lower AP threshold potential compared to LAP MSNs $\left(F_{1,66}=8.682, p<0.01\right.$; Figure 1D). Cells from replicate 2 animals also exhibited a lower AP threshold potential than those from replicate $3\left(F_{1,66}=8.684, p<0.01\right.$; Table S1). No line differences were found for AP half-width or peak amplitude ( $p$ 's $>0.05$, Figures 1E-F), although APs from replicate 3 cells had a slightly larger peak amplitude $\left(F_{1,66}=5.23, p<0.05\right.$; Table S1). Throughout the positive current steps (+50-400 pA), significantly more frequent APs were generated in HAP MSNs relative to LAP MSNs $\left(F_{1,66}=16.773, p<0.001\right.$; Figure $1 G, H)$.

Within the DMS (recording location depicted in Figure 2A), no clear line differences in excitability were observed. RMP was similar in both lines ( $p>0.05$; Figure $2 B$ ), although a main effect of replicate indicated that cells from replicate 3 animals sat at a more depolarized RMP $\left(F_{1,63}=24.72, p<0.001\right.$; Table S1). Line and sex were not significant factors for input resistance ( $p$ 's>0.05; Figure $2 C$ ), however a significant line $\times$ sex $\times$ replicate interaction revealed that within LAP2 cells, those from female mice exhibited greater input resistance relative to male cells $\left(F_{1,63}=7.626, p<0.01\right.$; Table $\left.S 1\right)$. No line or sex differences were found in AP threshold ( $p$ 's $>0.05$; Figure 2D), however replicate 2 cells exhibited a significantly lower AP threshold than those from replicate $3\left(F_{1,63}=5.446, p<0.05\right.$; Table S1).

No main effects of line or sex were found for AP half-width or peak amplitude ( $p$ 's $>0.05$;

Figures $2 \mathrm{E}-\mathrm{F}$ ), although replicate 3 cells demonstrated a wider AP half-width than replicate 2 cells $\left(F_{1,63}=8.665, p<0.01\right.$; Table $\left.S 1\right)$. In addition, a complex line $\times$ sex $\times$ replicate interaction revealed that within replicate 3 male cells, the AP half-width in LAP cells was significantly wider than in HAP cells $\left(F_{1,63}=6.981, p<0.05\right.$; Table S1). Analysis of AP frequency yielded no main effects of line, sex, or replicate $(p$ 's $>0.05$; Figures $2 \mathrm{G}-\mathrm{H}$ ). A significant line $\times \operatorname{sex} \times$ replicate interaction, however, found that within HAP3 cells, those from female mice fired significantly more frequent APs in response to current injection compared to those from male mice $\left(F_{1,63}=8.362, p<0.01\right.$; Table S1). 


\section{Excitatory transmission}

Spontaneous glutamate-driven currents were measured to evaluate excitatory input to MSNs. Within DLS, a line $\times$ replicate interaction for SEPSC frequency identified significantly higher frequencies in HAP2 MSNs compared to LAP2 MSNs $\left(F_{1,75}=6.572, p<0.05\right.$; Figure $3 A)$. Neither line nor sex were significant factors for sEPSC amplitude, rise time, or decay ( $p$ s $>0.05$; Figures $3 B, C, D$ ), although replicate 2 cells were found to have a significantly slower rise time compared to those from replicate $3\left(F_{1,75}=4.22, p<0.05\right.$; Table S1).

sEPSC frequency within DMS was significantly greater in HAP cells compared to LAP cells $\left(F_{1,69}=12.306, p<0.001\right.$; Figure $\left.3 F\right)$. A significant line $\times$ replicate interaction indicated that this difference was particularly large between HAP2 and LAP2 MSNs $\left(F_{1,69}=7.048\right.$; $p<0.01$; Table S1). A line difference was also found for sEPSC amplitude with significantly lower amplitudes in HAP compared to LAP cells $\left(F_{1,69}=7.242, p<0.01\right.$; Figure $\left.3 G\right)$. Analysis of rise time yielded a significant line $\times$ replicate interaction with HAP3 cells having a significantly shorter rise time than LAP3 cells $\left(F_{1,69}=5.938, p<0.05\right.$; Figure $\left.3 \mathrm{H}\right)$. No main effects or interactions reached statistical significance for decay $(p>0.05$; Figure $3 \mathrm{I})$.

AMPA/NMDA ratios measured in the DLS $\left(F_{1,64}=11.719, p<0.001\right.$; Figure $\left.4 A, C\right)$ and DMS $\left(F_{1,65}=4.748 ; p<0.05\right.$; Figure $\left.4 \mathrm{~B}, \mathrm{D}\right)$ of HAP mice were significantly lower than those observed in LAP mice. In addition, a significant line $\times$ sex interaction for DMS data indicated that this difference was particularly strong in male animals $\left(F_{1,65}=5.027, p<0.05\right.$; Table $\left.S 1\right)$.

\section{Inhibitory Transmission}

Within the DLS, HAP MSNs received more frequent inhibitory input compared to LAP MSNs $\left(F_{1,78}=5.125, p<0.05\right.$; Figure $\left.5 \mathrm{~A}\right)$. sIPSC frequency was also significantly greater in replicate 2 cells relative to replicate $3\left(F_{1,78}=13.897 ; p<0.001\right.$; Table $\left.S 1\right)$. The amplitude of sIPSCs in HAP cells was significantly larger than that seen in LAP MSNs $\left(F_{1,78}=5.413\right.$, $p<0.05$; Figure 5B). Analyses of sIPSC rise time and decay yielded no main effect of line ( $p$ 's $>0.05$; Figure $5 C, D$ ). Significant replicate $\times$ sex interactions for rise time and decay indicated significantly slower rise times for cells from replicate 2 male mice compared to 
those from replicate 2 females $\left(F_{1,78}=10.253, p<0.01\right.$; Table S1) and significantly shorter decay times for replicate 2 female cells compared to replicate 3 female cells $\left(F_{1,78}=4.529\right.$, $p<0.05$; Table S1).

Within the DMS, a trend towards greater sIPSC frequency within HAP versus LAP was observed $\left(F_{1,84}=3.555, p=0.06\right.$; Figure $\left.5 F\right)$. Analyses of postsynaptic measure of amplitude, rise time, and decay (Figure 5G,H,I), however, yielded no significant main effects or interactions ( $p$ 's $>0.05)$.

\section{DISCUSSION}

The above experiments demonstrated that genetic predisposition for high or low alcohol consumption produced subregion-specific differences in dorsal striatal neurotransmission (summary of electrophysiology results in Table 1). Specifically within the DLS, HAP MSNs were more excitable than LAP MSNs. Glutamate release was also elevated in HAP DLS and DMS, however this was accompanied by a complementary increase in GABA transmission. Additionally, lower observed AMPA/NMDA ratios in both subregions of HAP mice, another facet of glutamate transmission, suggests line differences in post-synaptic glutamate receptor characteristics. Collectively, these data indicate that the basal functional state of HAP DLS and DMS are substantially and significantly different from LAP DLS and DMS.

Assessment of the intrinsic physiological properties of neurons provides information about their excitability, or the likelihood of AP firing. These intrinsic properties are influenced by a variety of factors including conductance through various ion channels and/or the activity of ion pumps (Llinás, 1988). Genetic line effects on these intrinsic parameters may reflect differences in the quantity, subtype, localization, or post-translational functional modifications of ion channels or other proteins (Curran and Mohler, 2015). Protracted alcohol exposure increases neuronal excitability in numerous brain regions, including the striatum (Marty and Spigelman, 2012). Within the DLS, primary genetic line differences were found for input resistance, and AP threshold potential (Figure 1). These cells also fired more frequent APs in response to current injection. Strikingly, no line differences were observed within the 
DMS, thus indicating a subregion-specific effect of genetic background. Some possible mechanisms for this functional difference are that HAP MSNs may have lower conductance though particular $\mathrm{K}+$ channels and/or increased conductance through voltage-gated $\mathrm{Na}+$ channels at lower membrane potentials (Johnston et al., 2010; Kruger and Isom, 2016). Ultimately, this experiment determined that HAP MSNs within the DLS fired more APs in response to escalating current injection. This increased intrinsic excitability likely translates to larger DLS output compared to the output of LAP DLS, although this will require deeper exploration in the future. Prior studies have shown that the DLS governs habitual alcohol seeking (Corbit et al., 2012; 2014) Therefore, increased excitability may be a predisposing phenotype influencing excessive alcohol consumption in HAP mice.

As the primary excitatory neurotransmitter in the central nervous system, alterations in glutamate transmission can have wide-reaching effects on the activity of neurons and neural circuits. Elevated glutamate transmission is also a hallmark of AUD in humans (Quednow and Herdener, 2016). Prior work in non-human primates demonstrated that chronic alcohol exposure (up to 30 months) increased glutamate transmission within the putamen, a region analogous to the rodent DLS (Cuzon Carlson et al., 2011). Lesser alcohol intake ( 6 weeks) in a mouse model of binge-like drinking, however, observed no change in glutamate transmission in either the DMS or DLS of inbred C57BL/6J mice (Wilcox et al., 2014). Data from other alcohol-preferring selectively-bred rodent lines suggests that glutamate transmission is an important factor in their high-drinking phenotype. Although not directly assessed within the dorsal striatum subregions, 8 weeks of alcohol consumption increased extracellular glutamate levels in mesolimbic regions of alcohol-preferring $\mathrm{P}$ rats by as much as $100 \%$ (Ding et al., 2013). Additionally, pharmacological manipulation of various metabotropic glutamate receptors significantly influences alcohol seeking and relapse behavior in P rats (Besheer et al., 2010; Czachowski et al., 2012; Rodd et al., 2006). The current study demonstrated an increase in SEPSC frequency in HAP compared to LAP cells in both DLS and DMS (Figure 3). sEPSC event frequency is an index of neurotransmitter release from presynaptic terminals. Therefore, excitatory upstream cortical, thalamic, or amygdalar projections to dorsal striatum in HAP mice may be more excitable or have more 
efficient vesicle release mechanisms than LAP mice. It is possible that more frequent spontaneous glutamate release could explain the greater excitability observed in HAP DLS MSNs, however the coinciding greater frequency of GABA-mediated sIPSCs in DLS (Figure 5) suggests that excitation/inhibition balance mechanisms may be in effect (discussed further below). Additionally, the postsynaptic parameters of sEPSC amplitude and rise time were both found to be decreased in HAP DMS (Figure 3). Reduced amplitude may indicate reduced AMPA receptor surface expression. However, faster ion channel kinetics, as determined by a shorter SEPSC rise time, may reflect functional compensation. Our data are consistent with the above previous observations of elevated glutamate transmission in animal models of chronic alcohol consumption. It is important to bear in mind, however, that the mice used in the current study were alcohol-naïve. As such, our experiments probed the effect of genetic background, not direct alcohol exposure. Nevertheless, a family history of high alcohol intake produced significantly higher basal glutamate transmission in both the DLS and DMS relative to a history of alcohol avoidance.

An assessment of the ratio of postsynaptic AMPA to NMDA receptor-driven current can reveal other important functional differences in excitatory transmission. An increase in the AMPA/NMDA current ratio can be produced by repeated drug exposure in certain brain regions (Thomas et al., 2008) and is often interpreted as increased excitatory transmission, likely reflecting higher numbers of functional, membrane-bound AMPA receptors. However, an increase in NMDA receptor function would decrease this ratio, even though it too, reflects an increase in excitatory transmission. Indeed, repeated alcohol exposure is known to upregulate particular NMDA receptor subunits in brain (Chen et al., 2018; Nagy, 2004). This adaptation may be tied to the hyperexcitability observed in the CNS during alcohol withdrawal, an effect which may drive relapse behavior (Krystal et al., 2003). Repeated alcohol exposure increases NMDA receptor function in the DMS of rats (Wang et al., 2010). A variety of NMDA receptor antagonists also reduced alcohol consumption of selectivelybred alcohol preferring rats (Malpass et al., 2010; McMillen et al., 2004). Interestingly, the current study found substantially lower AMPA/NMDA ratios in both the DLS and DMS of HAP mice compared to LAP mice (Figure 4). Considering no line difference was observed 
for sEPSC amplitude in the DLS, the lower ratio in this region might reflect of an increase in NMDA receptor function rather than a decrease in AMPA receptor function or number. Within the DMS, however, a slightly reduced sEPSC amplitude in HAP mice suggests lower numbers of AMPA receptors could explain the smaller ratio in this region. Future work will more deeply probe the molecular dynamics that underlie the differing AMPA to NMDA current ratios between these selected lines.

Repeated alcohol exposure has also been shown to alter dorsal striatal GABA transmission. Rodents and non-human primates exhibit a reduction in miniature IPSC frequency and amplitude following long periods of repeated alcohol consumption, thus indicating both pre- and postsynaptic changes (Wilcox et al., 2014; Cuzon Carlson et al., $2011 ; 2018)$. Chronic alcohol exposure significantly reduces $G_{A B A_{A}}$ receptor numbers and alters subunit expression (Kumar et al., 2009), an effect that is also seen specifically in selectively-bred alcohol-preferring rats (McClintick et al., 2015). This reduction in GABA transmission could translate to a disinhibition of MSNs, thus increasing the likelihood of MSN output. However, in the current study, HAP mice were observed to have more frequent presynaptic GABA input relative to LAP mice in both DLS and DMS (Figure 4). Additionally, the postsynaptic parameter of amplitude was larger in HAP DLS. As previously mentioned, this was also met with significantly more frequent glutamate transmission in HAP dorsal striatum. This could be reflective of excitation/inhibition balance, wherein increases/decreases in excitatory transmission are met with compensatory inhibition to achieve a state of balance. In disease states such as addiction, this balance can be disrupted and particular neurocircuits can be pathologically over- or underactive (Yizhar et al., 2011). Within striatal circuitry, it is important to distinguish between the 'direct' and 'indirect' pathways that either promote or inhibit behavioral action patterns, respectively. Indeed, previous work has demonstrated that excessive alcohol intake in mice resulted in increased glutamatergic input onto direct pathways MSNs as well as increased GABA input onto indirect pathway MSNs (Cheng et al., 2017), thus resulting in much higher ratio of direct pathway output compared to indirect pathway output. This pathway imbalance may reflect an overall reduced ability to inhibit highly active alcohol-seeking behavior. In the absence of 
alcohol exposure in the current study, no clear evidence of excitation/inhibition imbalance was observed in either line. However, given the previous findings mentioned above, distinguishing GABA and glutamate transmission onto pathway-specific MSNs will be an important future step towards clarifying how net MSN input/output is affected by genetic selection for alcohol preference. It will also be important to evaluate how alcohol consumption in HAP mice influences these parameters in the future.

In conclusion, the current study demonstrated that family histories of high or low alcohol consumption can significantly affect basal neurotransmission within the dorsal striatum. These different functional states may interact with alcohol exposure in a way that promotes/inhibits further alcohol consumption. It is important to note that the origin of the selected lines was from a bidirectional selection and thus genetic and physiological differences could alternatively underlie a predisposition for alcohol avoidance in LAP mice rather than an increased predisposition for alcohol preference in HAP mice. Unfortunately, the genetically heterogeneous HS/lbg stock, the one from which HAP and LAP mice were originally selected, that would serve as a wildtype control line no longer exists. Nevertheless, there are clear functional differences produced by this genetic divergence that indicate that dorsal striatal neurotransmission is indeed related to relative AUD risk. The strongest evidence for genetic correlation (Table 1) points to increased excitability of DLS MSNs in individuals with a positive family history of excessive alcohol intake relative to those with a family history of low alcohol intake. This provides an attractive hypothesis that elevated excitability/activity of DLS MSNs may be a predisposing phenotype for future problematic alcohol seeking and/or consumption. Future work will evaluate how these basal electrophysiological measures in the HAP and LAP selected lines are altered by alcohol exposure. In addition, examination of line differences in dorsal striatal synaptic plasticity may offer valuable insight concerning their capacity for behavioral flexibility (Gremel and Costa, 2013), a phenomenon which is associated with addictive potential. Furthermore, in the future it will be important to define the molecular mechanisms underlying these neurophysiological differences we measured here. Once these are determined, we may begin to elucidate the complex relationship between differential gene expression, neuronal function, and the 
endophenotypes of these selected mouse lines that may offer novel insights into the development of alcohol abuse in those with a genetic predisposition for AUDs.

\section{AUTHOR CONTRIBUTIONS}

BMF and BKA were responsible for study concept and design. BMF and BM collected electrophysiology data. BMF conducted statistical analysis for electrophysiology data. BMF drafted the manuscript. BM and BKA provided critical revision of the manuscript for intellectual content. All authors critically reviewed content and approved the final version of the manuscript for publication. The authors have no conflicts of interest to declare.

\section{ACKNOWLEDGMENTS}

We wish to thank Dr. Nick Grahame for supplying HAP and LAP mice. This work was supported by NIAAA grants T32 AA07462 (BMF), F32 AA026488 (BMF), R00 AA023507 (BKA), R01 AA027214 (BKA), and P60 AA007611 (Indiana Alcohol Research Center). 


\section{REFERENCES}

Adermark, L., Jonsson, S., Ericson, M., and Söderpalm, B. (2011) Intermittent ethanol consumption depresses endocannabinoid-signaling in the dorsolateral striatum of rat. Neuropharmacology 61:1160-1165.

Balleine, B.W., and O'Doherty, J.P. (2010) Human and rodent homologies in action control: corticostriatal determinants of goal-directed and habitual action. Neuropsychopharmacology 35:48-69.

Besheer, J., Grondin, J.J.M., Cannady, R., Sharko, A.C., Faccidomo, S., and Hodge, C.W. (2010) Metabotropic glutamate receptor 5 activity in the nucleus accumbens is required for the maintenance of ethanol self-administration in a rat genetic model of high alcohol intake. Biological Psychiatry 67:812-822.

Bjork, J.M., Knutson, B., and Hommer, D.W. (2008) Incentive-elicited striatal activation in adolescent children of alcoholics. Addiction (Abingdon, England) 103:1308-1319.

Chen, J., Ma, Y., Fan, R., Yang, Z., and Li, M.D. (2018) Implication of genes for the Nmethyl-d-aspartate (NMDA) receptor in substance addictions. Molecular neurobiology 55:7567-7578.

Cheng, Y., Huang, C.C.Y., Ma, T., Wei, X., Wang, X., Lu, J., and Wang, J. (2017) Distinct synaptic strengthening of the striatal direct and indirect pathways drives alcohol consumption. Biol Psychiatry 81:918-929.

Corbit, L.H., Nie, H., and Janak, P.H. (2012) Habitual alcohol seeking: time course and the contribution of subregions of the dorsal striatum. Biological psychiatry 72:389-395.

Corbit, L.H., Nie, H., and Janak, P.H. (2014) Habitual responding for alcohol depends upon both AMPA and D2 receptor signaling in the dorsolateral striatum. Frontiers in behavioral neuroscience 8:301-301.

Crabbe, J.C., Phillips, T.J., Kosobud, A., and Belknap, J.K. (1990) Estimation of genetic correlation: interpretation of experiments using selectively bred and inbred animals. Alcoholism, clinical and experimental research 14:141-151. 
Curran, J., and Mohler, P. (2015) Alternative paradigms for ion channelopathies: Disorders of ion channel membrane trafficking and posttranslational modification. Annual Review of Physiology 77:505-524.

Cuzon Carlson, V.C., Grant, K.A., and Lovinger, D.M. (2018) Synaptic adaptations to chronic ethanol intake in male rhesus monkey dorsal striatum depend on age of drinking onset. Neuropharmacology 131:128-142.

Cuzon Carlson, V.C., Seabold, G.K., Helms, C.M., Garg, N., Odagiri, M., Rau, A.R., Daunais, J., Alvarez, V.A., Lovinger, D.M., and Grant, K.A. (2011) Synaptic and morphological neuroadaptations in the putamen associated with long-term, relapsing alcohol drinking in primates. Neuropsychopharmacology 36:2513.

Czachowski, C.L., DeLory, M.J., and Pope, J.D. (2012) Behavioral and neurotransmitter specific roles for the ventral tegmental area in reinforcer-seeking and intake. Alcoholism: Clinical and Experimental Research 36:1659-1668.

Ding, Z.-M., Rodd, Z.A., Engleman, E.A., Bailey, J.A., Lahiri, D.K., and McBride, W.J. (2013) Alcohol drinking and deprivation alter basal extracellular glutamate concentrations and clearance in the mesolimbic system of alcohol-preferring $(P)$ rats. Addiction Biology 18:297-306.

Everitt, B.J., and Robbins, T.W. (2016) Drug addiction: Updating actions to habits to compulsions ten years on. Annu Rev Psychol 67:23-50.

Fritz, B.M., and Boehm, S.L., 2nd (2014) The effect of prior alcohol consumption on the ataxic response to alcohol in high-alcohol preferring mice. Alcohol 48:765-772.

Fritz, B.M., Grahame, N.J., and Boehm, S.L., 2nd (2013) Selection for high alcohol preference drinking in mice results in heightened sensitivity and rapid development of acute functional tolerance to alcohol's ataxic effects. Genes, brain, and behavior 12:78-86.

Gremel, C.M., and Costa, R.M. (2013) Orbitofrontal and striatal circuits dynamically encode the shift between goal-directed and habitual actions. Nature communications 4:2264. 
Heitzeg, M.M., Nigg, J.T., Yau, W.Y., Zucker, R.A., and Zubieta, J.K. (2010) Striatal dysfunction marks preexisting risk and medial prefrontal dysfunction is related to problem drinking in children of alcoholics. Biol Psychiatry 68:287-295.

Hunnicutt, B.J., Jongbloets, B.C., Birdsong, W.T., Gertz, K.J., Zhong, H., and Mao, T. (2016) A comprehensive excitatory input map of the striatum reveals novel functional organization. Elife 5:e19103.

Johnston, J., Forsythe, I.D., and Kopp-Scheinpflug, C. (2010) SYMPOSIUM REVIEW: Going native: voltage-gated potassium channels controlling neuronal excitability. The Journal of physiology 588:3187-3200.

Kendler, K.S., Ohlsson, H., Bacanu, S., Sundquist, J., and Sundquist, K. (2018) The risk for drug abuse, alcohol use disorder, and psychosocial dysfunction in offspring from high-density pedigrees: its moderation by personal, family, and community factors. Molecular psychiatry.

Kruger, L.C., and Isom, L.L. (2016) Voltage-gated Na+ channels: Not just for conduction. Cold Spring Harbor perspectives in biology 8:a029264.

Krystal, J.H., Petrakis, I.L., Mason, G., Trevisan, L., and D'Souza, D.C. (2003) N-methyl-Daspartate glutamate receptors and alcoholism: reward, dependence, treatment, and vulnerability. Pharmacology \& therapeutics 99:79-94.

Kumar, S., Porcu, P., Werner, D.F., Matthews, D.B., Diaz-Granados, J.L., Helfand, R.S., and Morrow, A.L. (2009) The role of GABA A receptors in the acute and chronic effects of ethanol: a decade of progress. Psychopharmacology 205:529-564.

Linsenbardt, D.N., and Boehm, S.L., 2nd (2015) Relative fluid novelty differentially alters the time course of limited-access ethanol and water intake in selectively bred highalcohol-preferring mice. Alcoholism, clinical and experimental research 39:621-630.

Llinás, R.R. (1988) The intrinsic electrophysiological properties of mammalian neurons: insights into central nervous system function. Science 242:1654-1664.

Malpass, G.E., Williams, H.L., and McMillen, B.A. (2010) Effects of the non-competitive NMDA receptor antagonist memantine on the volitional consumption of ethanol by alcohol-preferring rats. Basic \& clinical pharmacology \& toxicology 106:435-444. 
Marty, V.N., and Spigelman, I. (2012) Effects of alcohol on the membrane excitability and synaptic transmission of medium spiny neurons in the nucleus accumbens. Alcohol 46:317-327.

Matson, L.M., and Grahame, N.J. (2013) Pharmacologically relevant intake during chronic, free-choice drinking rhythms in selectively bred high alcohol-preferring mice. Addict Biol 18:921-929.

McClintick, J.N., McBride, W.J., Bell, R.L., Ding, Z.-M., Liu, Y., Xuei, X., and Edenberg, H.J. (2015) Gene expression changes in serotonin, GABA-A receptors, neuropeptides and ion channels in the dorsal raphe nucleus of adolescent alcohol-preferring $(P)$ rats following binge-like alcohol drinking. Pharmacology Biochemistry and Behavior 129:87-96.

McMillen, B.A., Joyner, P.W., Parmar, C.A., Tyer, W.E., and Williams, H.L. (2004) Effects of NMDA glutamate receptor antagonist drugs on the volitional consumption of ethanol by a genetic drinking rat. Brain research bulletin 64:279-284.

Munoz, B., Fritz, B.M., Yin, F., and Atwood, B.K. (2018) Alcohol exposure disrupts mu opioid receptor-mediated long-term depression at insular cortex inputs to dorsolateral striatum. Nat Commun 9:1318.

Nagy, J. (2004) The NR2B subtype of NMDA receptor: a potential target for the treatment of alcohol dependence. Current Drug Targets-CNS \& Neurological Disorders 3:169-179.

Nam, H.W., Hinton, D.J., Kang, N.Y., Kim, T., Lee, M.R., Oliveros, A., Adams, C., Ruby, C.L., and Choi, D.S. (2013) Adenosine transporter ENT1 regulates the acquisition of goal-directed behavior and ethanol drinking through A2A receptor in the dorsomedial striatum. The Journal of neuroscience : the official journal of the Society for Neuroscience 33:4329-4338.

Oberlin, B., Best, C., Matson, L., Henderson, A., and Grahame, N. (2011) Derivation and characterization of replicate high- and low-alcohol preferring lines of mice and a highdrinking crossed HAP line. Behavior genetics 41:288-302. 
Oberlin, B.G., and Grahame, N.J. (2009) High-alcohol preferring mice are more impulsive than low-alcohol preferring mice as measured in the delay discounting task. Alcoholism, clinical and experimental research 33:1294-1303.

Quednow, B.B., and Herdener, M. (2016) Human pharmacology for addiction medicine: From evidence to clinical recommendations. In: Progress in Brain Research. $\mathrm{H}$. Ekhtiari, and M. Paulus (eds). Elsevier, pp. 227-250.

Rodd, Z.A., McKinzie, D.L., Bell, R.L., McQueen, V.K., Murphy, J.M., Schoepp, D.D., and McBride, W.J. (2006) The metabotropic glutamate 2/3 receptor agonist LY404039 reduces alcohol-seeking but not alcohol self-administration in alcohol-preferring $(P)$ rats. Behavioural Brain Research 171:207-215.

Sah, P., Hestrin, S., and Nicoll, R. (1989) Tonic activation of NMDA receptors by ambient glutamate enhances excitability of neurons. Science 246:815-818.

Sjoerds, Z., de Wit, S., van den Brink, W., Robbins, T.W., Beekman, A.T., Penninx, B.W., and Veltman, D.J. (2013) Behavioral and neuroimaging evidence for overreliance on habit learning in alcohol-dependent patients. Translational psychiatry 3:e337.

Soriano, F.X., Papadia, S., Hofmann, F., Hardingham, N.R., Bading, H., and Hardingham, G.E. (2006) Preconditioning doses of NMDA promote neuroprotection by enhancing neuronal excitability. Journal of Neuroscience 26:4509-4518.

Tepper, J.M., and Bolam, J.P. (2004) Functional diversity and specificity of neostriatal interneurons. Current opinion in neurobiology 14:685-692.

Thomas, M.J., Kalivas, P., and Shaham, Y. (2008) Neuroplasticity in the mesolimbic dopamine system and cocaine addiction. British journal of pharmacology 154:327342.

Tricomi, E., Balleine, B.W., and O'Doherty, J.P. (2009) A specific role for posterior dorsolateral striatum in human habit learning. The European journal of neuroscience 29:2225-2232.

Vollstadt-Klein, S., Wichert, S., Rabinstein, J., Buhler, M., Klein, O., Ende, G., Hermann, D., and Mann, K. (2010) Initial, habitual and compulsive alcohol use is characterized by a 
shift of cue processing from ventral to dorsal striatum. Addiction (Abingdon, England) 105:1741-1749.

Wang, J., Lanfranco, M.F., Gibb, S.L., Yowell, Q.V., Carnicella, S., and Ron, D. (2010) Longlasting adaptations of the NR2B-containing NMDA receptors in the dorsomedial striatum play a crucial role in alcohol consumption and relapse. The Journal of Neuroscience 30:10187-10198.

Wilcox, M.V., Carlson, V.C.C., Sherazee, N., Sprow, G.M., Bock, R., Thiele, T.E., Lovinger, D.M., and Alvarez, V.A. (2014) Repeated binge-like ethanol drinking alters ethanol drinking patterns and depresses striatal GABAergic transmission. Neuropsychopharmacology 39:579-594.

Yin, H.H., Knowlton, B.J., and Balleine, B.W. (2004) Lesions of dorsolateral striatum preserve outcome expectancy but disrupt habit formation in instrumental learning. The European journal of neuroscience 19:181-189.

Yizhar, O., Fenno, L.E., Prigge, M., Schneider, F., Davidson, T.J., O'shea, D.J., Sohal, V.S., Goshen, I., Finkelstein, J., and Paz, J.T. (2011) Neocortical excitation/inhibition balance in information processing and social dysfunction. Nature 477:171.

Yoon, G., Westermeyer, J., Kuskowski, M.A., and Nesheim, L. (2013) Impact of the number of parents with alcohol use disorder on alcohol use disorder in offspring: a populationbased study. The Journal of clinical psychiatry 74:795-801.

This article is protected by copyright. All rights reserved 
Figure 1. Dorsolateral striatal medium spiny neurons in HAP mice are hyperexcitable relative to LAP mice. A) Schematic of recording location for DLS MSNs. Measures of: B) resting membrane potential, C) input resistance, D) action potential threshold, E) action potential half-width, F) action potential peak amplitude, and $G, H$ ) frequency of action potentials with I) representative action potential traces from HAP (red) and LAP (blue) neurons stimulated with $-100-200$ pA of currents steps, separated by replicate. Scale bars= $200 \mathrm{~ms}, 50 \mathrm{mV}$. Data represent mean \pm SEM. ${ }^{*} p<0.05,{ }^{* *} p<0.01$ for main effect of line. Statistical analyses of sex, replicate, and interactions may be found in the main body of the text. $n=7-14$ cells per line/replicate/sex combination from 3-4 animals per each combination.

Figure 2. Dorsomedial striatal medium spiny neuron excitability does not differ between HAP and LAP mice. A) Schematic of recording location for DMS MSNs. B) Resting membrane potential, C) input resistance, D) action potential threshold, E) action potential half-width, F) action potential peak amplitude, and G-H) frequency of action potentials. I) Representative action potential traces from HAP (red) and LAP (blue) neurons stimulated with $-100-200 \mathrm{pA}$ of currents steps. Scale bars $=200 \mathrm{~ms}, 50 \mathrm{mV}$. Data represent mean \pm SEM. Statistical analyses of sex, replicate, and interactions may be found in the main body of the text. $n=7-13$ cells per line/replicate/sex combination from 3-4 animals per each combination.

\section{Figure 3. Dorsal striatal basal glutamate transmission differs between HAP and LAP} mice. Measures of spontaneous excitatory postsynaptic current (sEPSC): A,F) frequency, $B, G$ ) amplitude, $C, H$ ) rise time, and $D, I)$ decay constant. E,J) Representative sEPSC traces from HAP (red) and LAP (blue) MSNs. Scale bars $=500 \mathrm{~ms}, 10 \mathrm{pA}$. Bar graphs represent mean \pm SEM. ${ }^{* *} p<0.01$ for main effect of line; ${ }^{\$} p<0.05$ and ${ }^{\$} p<0.01$ for line $\times$ replicate interaction. Statistical analyses of sex, replicate, and other interactions may be found in the main body of the text. $n=10-14$ cells per line/replicate/sex combination from 3-5 animals per each combination. 
Figure 4. Dorsal striatal AMPA to NMDA current ratios are lower in HAP mice relative to LAP mice. The ratio of AMPA receptor-driven current (-80 $\mathrm{mV}$ holding potential) to that of NMDA receptor-driven current (+60 $\mathrm{mV}$ holding potential + NBQX treatment) in: A,C) DLS and $B, D)$ DMS. Representative AMPA and NMDA receptor-mediated current traces are from HAP (red) and LAP (blue) mouse MSNs. Scale bars $=500$ ms, 200 pA. Bar graphs represent \pm SEM. ${ }^{*} p<0.05$ and ${ }^{* *} p<0.01$ for main effect of line. Statistical analyses of sex, replicate, and interactions may be found in the main body of the text. $n=7-10$ cells per line/replicate/sex combination from 3-5 animals per each combination.

Figure 5. Basal inhibitory transmission is greater in HAP mice relative to LAP mice within the dorsolateral striatum. Measures of spontaneous inhibitory postsynaptic current (sEPSC): A,F) frequency, $B, G$ ) amplitude, $C, H$ ) rise time, and the $D, I$ ) decay constant. $E, J$ ) Representative sIPSC recording traces from HAP (red) and LAP (blue) MSNs. Scale bars $=500 \mathrm{~ms}, 50 \mathrm{pA}$. Bar graphs represent mean \pm SEM. ${ }^{*} p<0.05$ and ${ }^{* *} p<0.01$ for main effect of line. Statistical analyses of sex, replicate, and interactions may be found in the main body of the text. $n=8-14$ cells per line/replicate/sex combination from 3-5 animals per each combination.

Table 1. Summary of significant genetically 'correlated' physiological parameters in HAP and LAP mice using the methodology of Crabbe et al. (1990). 


\section{Excitability \\ DLS}

HAP > LAP

$+++$

DMS

sEPSC Frequency

DLS

HAP > LAP

$+$

DMS

HAP > LAP

$++$

sEPSC Amplitude

DLS

DMS

HAP $<$ LAP

$++$

sEPSC Rise-Time

DLS

DMS

HAP $<$ LAP

$+$

sIPSC Frequency

DLS

HAP > LAP

$++$

DMS

HAP > LAP

$+$

sIPSC Amplitude

DLS

HAP > LAP

$++$

DMS

AMPA/NMDA Ratio

DLS

HAP $<$ LAP

$+++$

DMS

HAP $<$ LAP

$++$

This article is protected by copyright. All rights reserved 


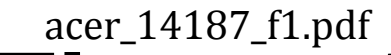
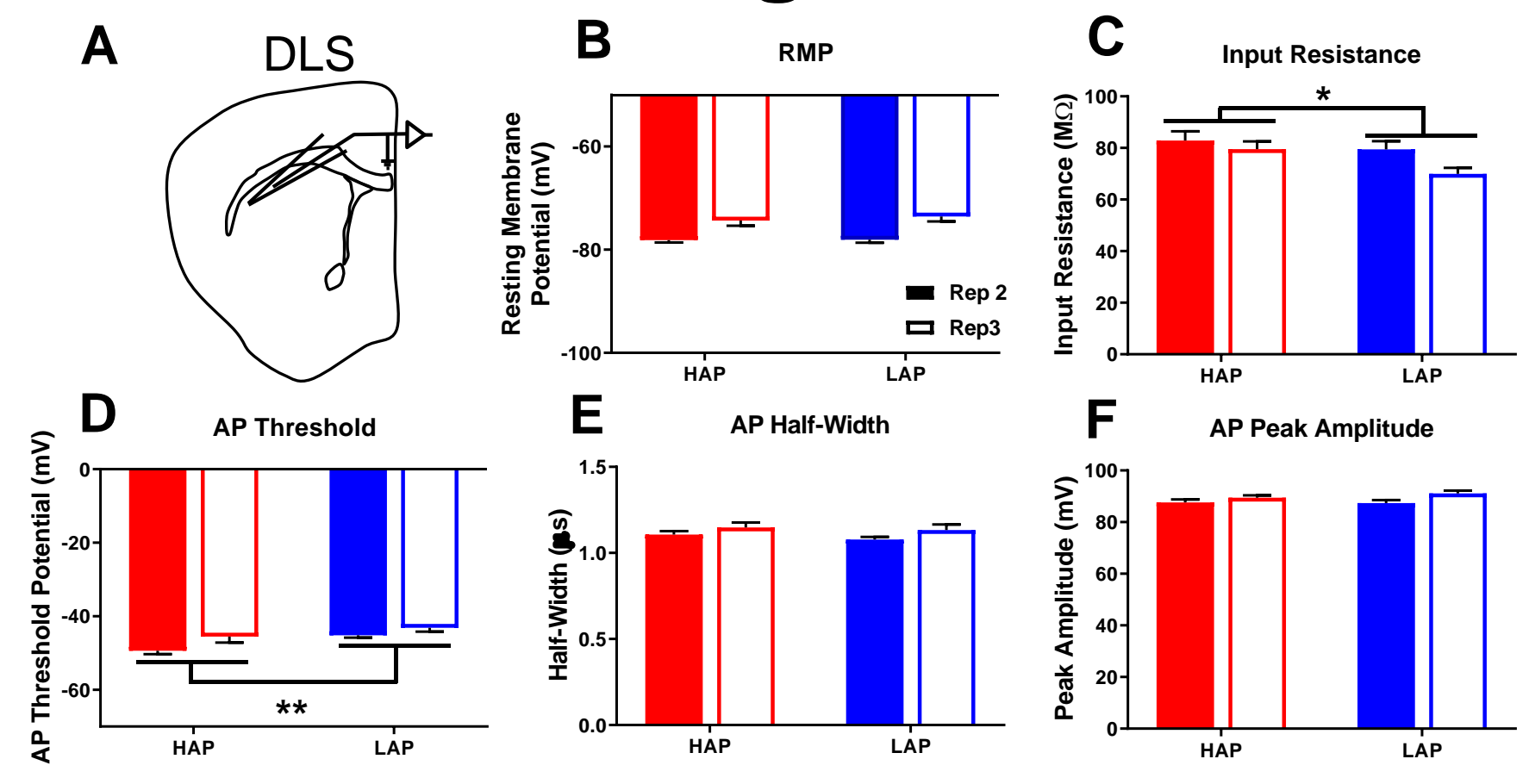

F AP Peak Amplitude
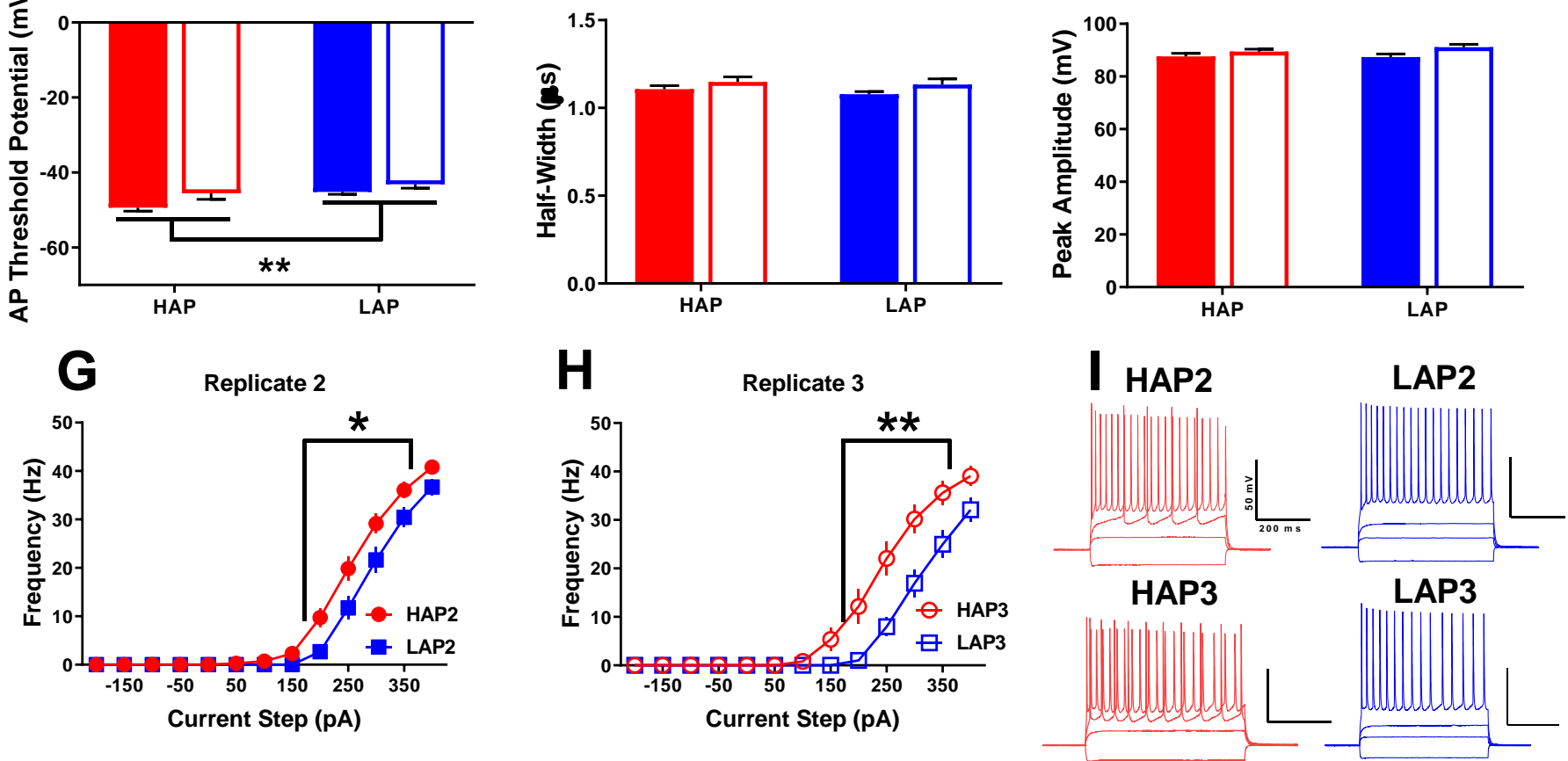
Figure 2
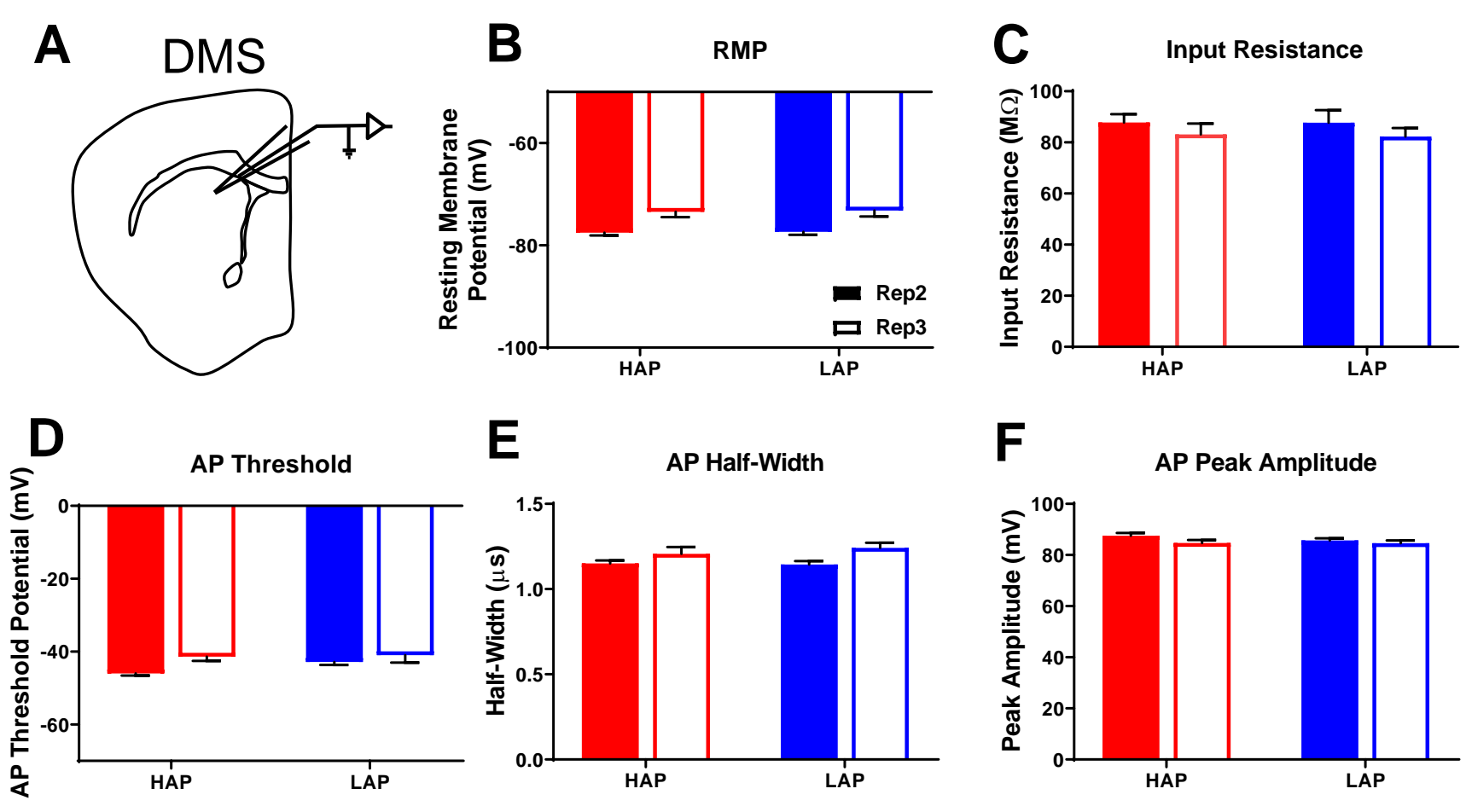

$\mathbf{F}$
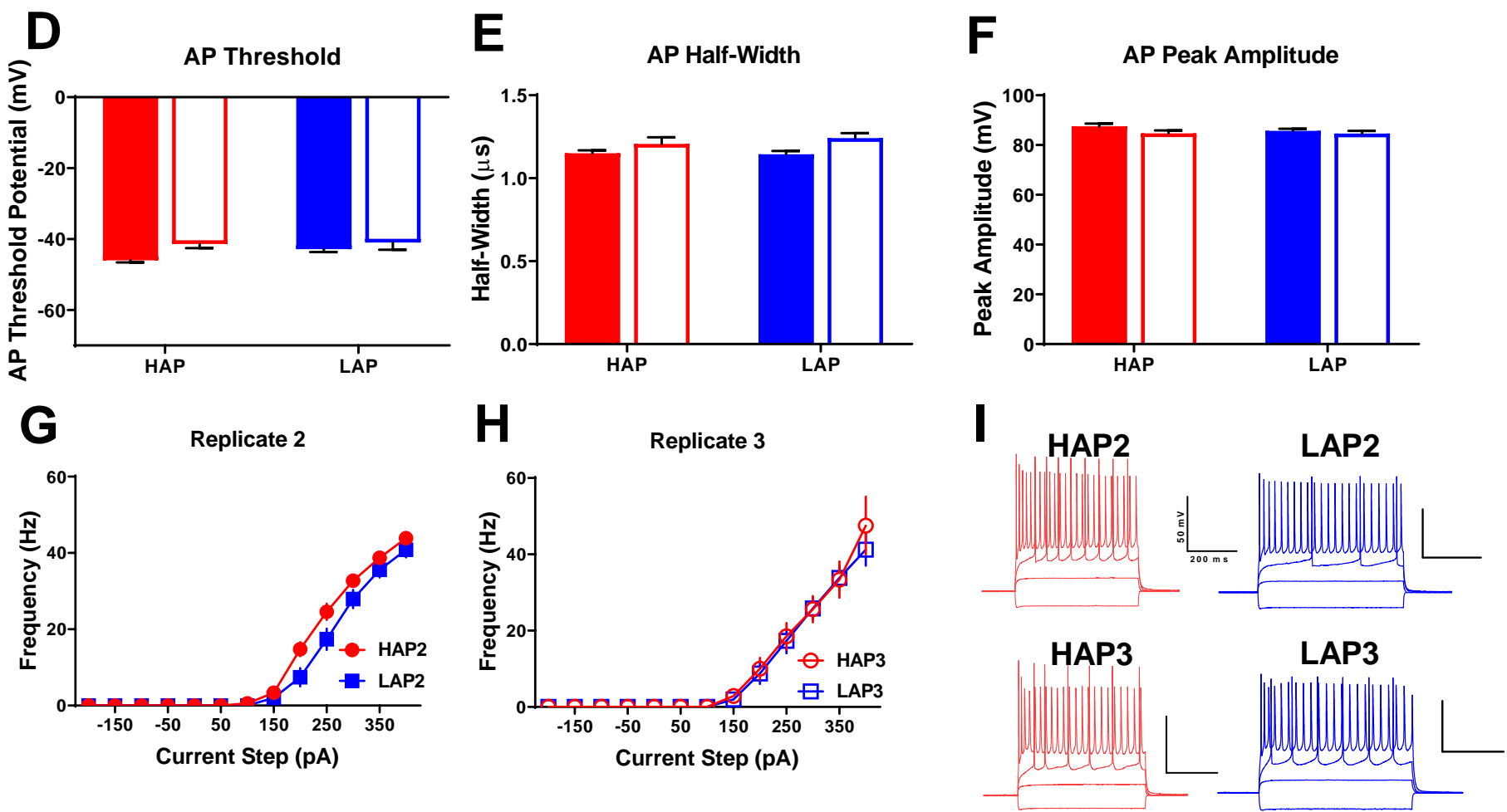


\section{Figure 3}
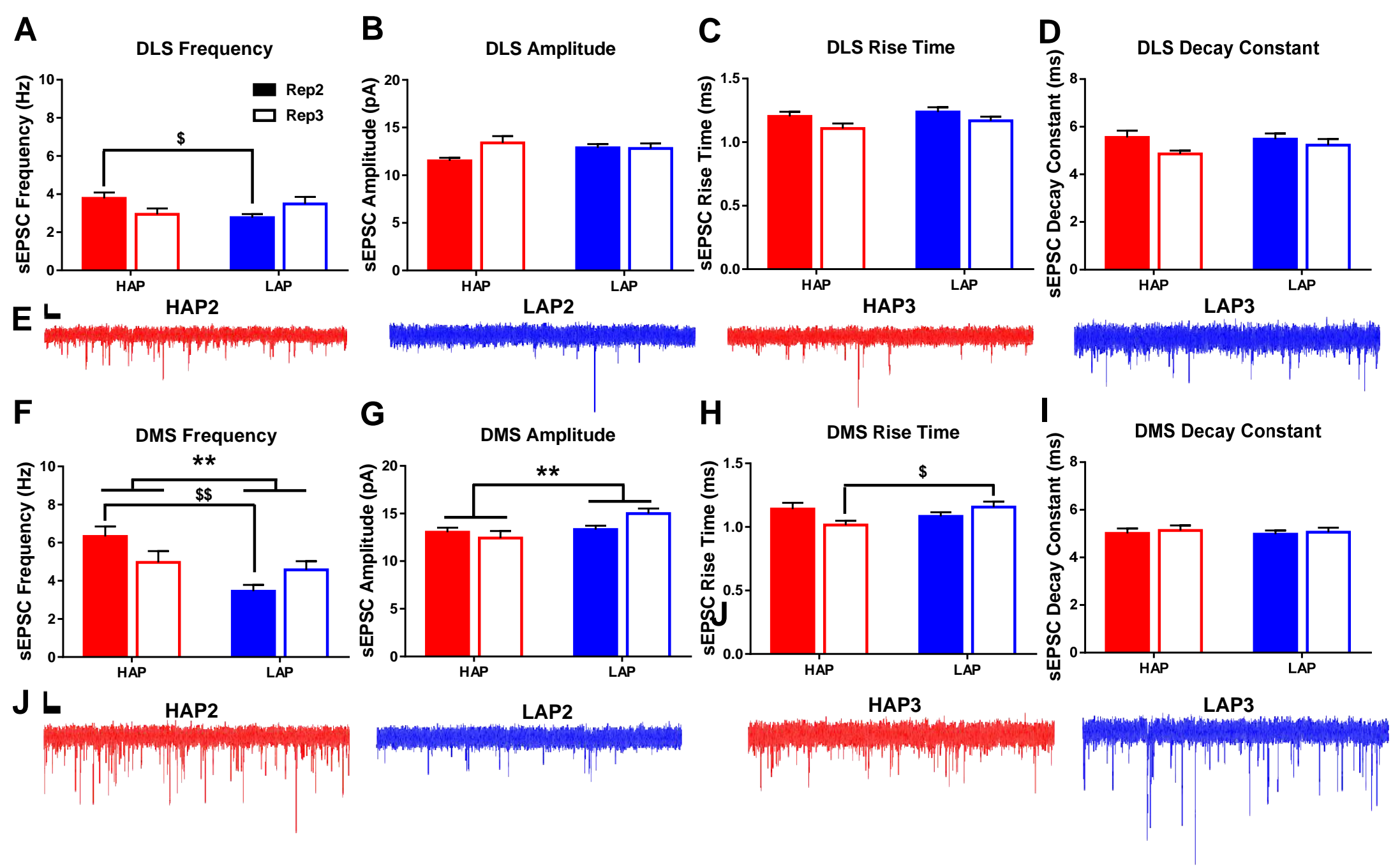

This article is protected by copyright. All rights reserved 


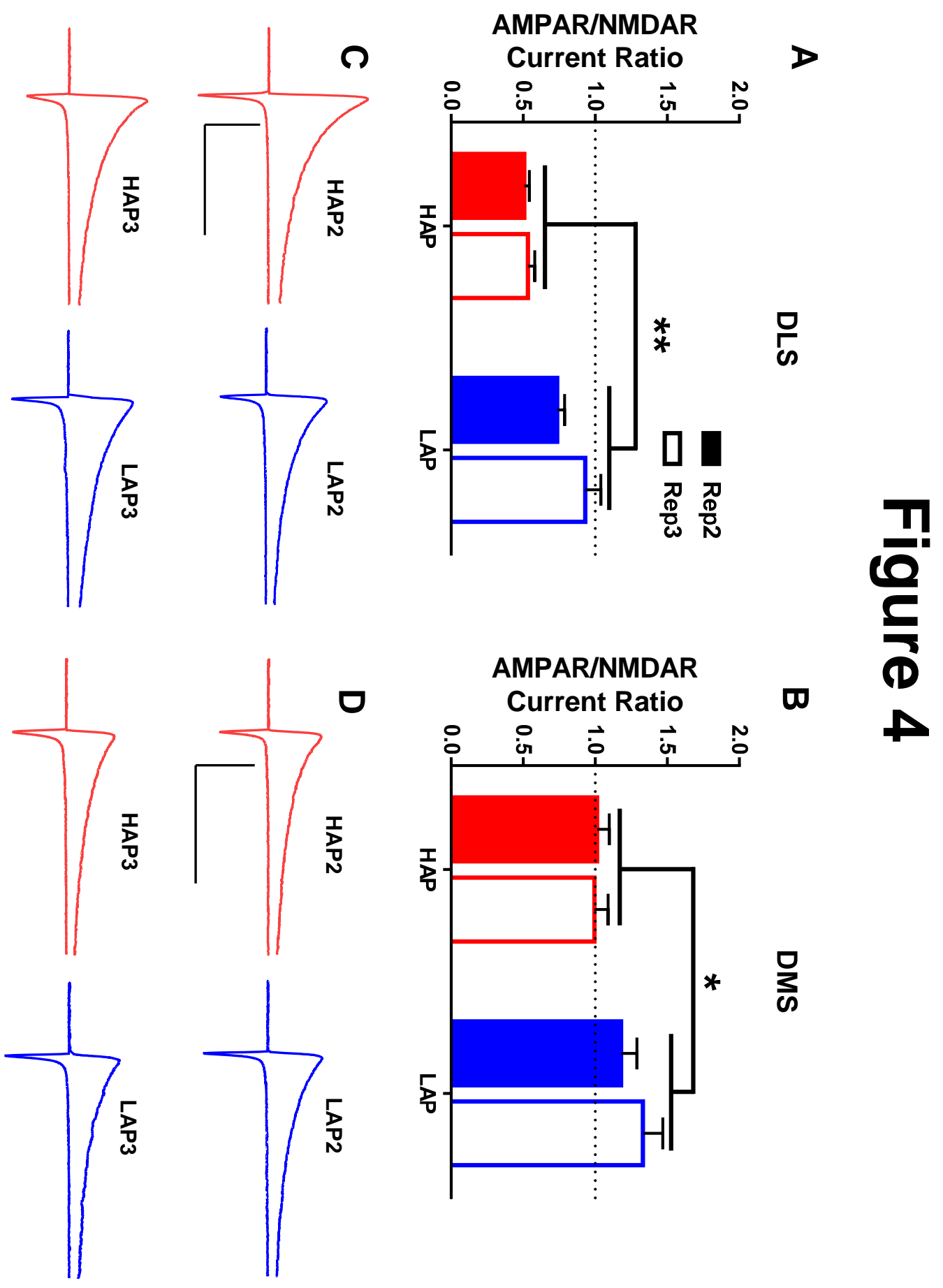


Figure 5

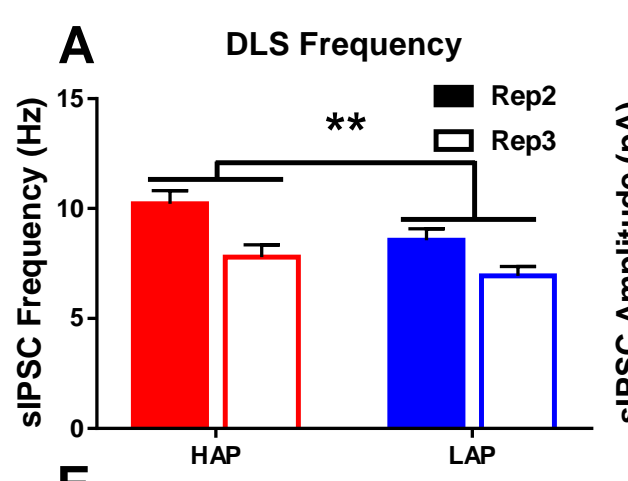

\section{B DLS Amplitude C}
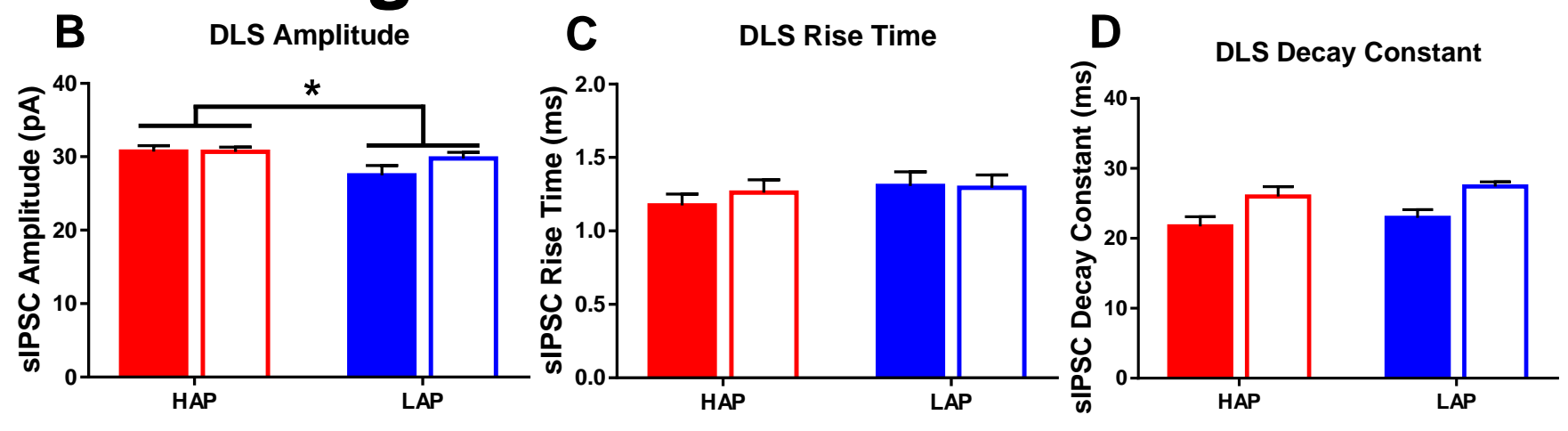

\section{E HAP2}

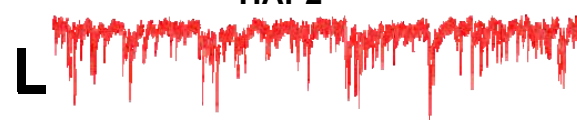

\section{LAP2}
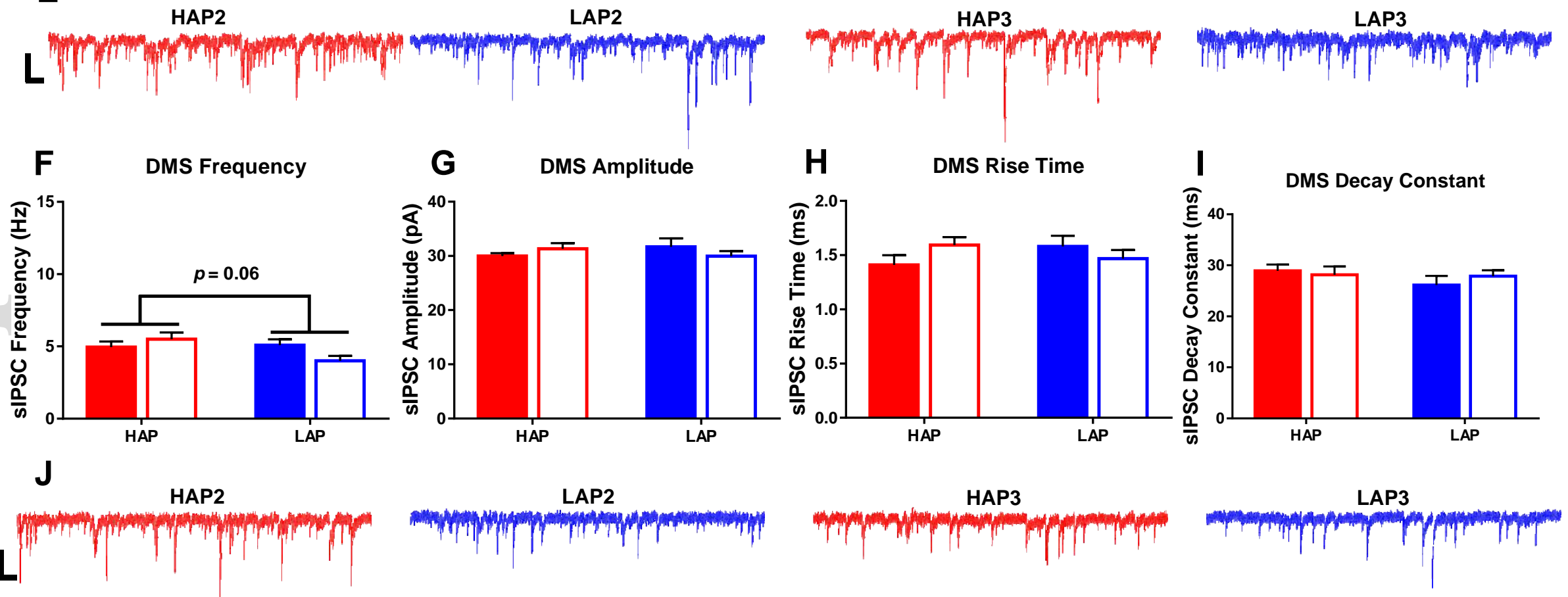